\title{
The Amyloidogenic V122I Transthyretin Variant in Elderly Black Americans
}

\author{
C. Cristina Quarta, M.D., Joel N. Buxbaum, M.D., Amil M. Shah, M.D., M.P.H., \\ Rodney H. Falk, M.D., Brian Claggett, Ph.D., Dalane W. Kitzman, M.D., \\ Thomas H. Mosley, Ph.D., Kenneth R. Butler, Ph.D., Eric Boerwinkle, Ph.D., \\ and Scott D. Solomon, M.D.
}

\begin{abstract}
BACKGROUND
Approximately 4\% of black Americans carry a valine-to-isoleucine substitution (V122I) in the transthyretin protein, which has been associated with late-onset restrictive amyloid cardiomyopathy and increased risks of death and heart failure.
\end{abstract}

\section{METHODS}

We determined genotype status for the transthyretin gene (TTR) in 3856 black participants in the Atherosclerosis Risk in Communities study and assessed clinical profiles, mortality, and the risk of incident heart failure in V122I TTR variant carriers (124 participants [3\%]) versus noncarriers (3732 participants). Cardiac structure and function and features suggestive of cardiac amyloidosis were assessed in participants who underwent echocardiography during visit 5 (2011 to 2013), when they were older than 65 years of age.

\section{RESULTS}

After 21.5 years of follow-up, we did not detect a significant difference in mortality between carriers (41 deaths, 33\%) and noncarriers (1382 deaths, 37\%; age- and sexstratified hazard ratio among carriers, $0.99 ; 95 \%$ confidence interval [CI], 0.73 to 1.36; $\mathrm{P}=0.97$ ). The TTR variant was associated with an increased risk of incident heart failure (age- and sex-stratified hazard ratio, 1.47; 95\% CI, 1.03 to 2.10; $\mathrm{P}=0.04$ ). On echocardiography at visit 5 , carriers (46 participants) had worse systolic and diastolic function, as well as a higher level of N-terminal pro-brain natriuretic peptide, than noncarriers (1194 participants), although carriers had a low prevalence (7\%) of overt manifestations of amyloid cardiomyopathy.

\section{CONCLUSIONS}

We did not detect a significant difference in mortality between V122I TTR allele carriers and noncarriers, a finding that contrasts with prior observations; however, the risk of heart failure was increased among carriers. The prevalence of overt cardiac abnormalities among V122I TTR carriers was low. (Funded by the National Heart, Lung, and Blood Institute and others.)
From the Division of Cardiovascular Medicine, Brigham and Women's Hospital, Harvard Medical School, Boston (C.C.Q., A.M.S., R.H.F., B.C., S.D.S.); Institute of Cardiology, University of Bologna and S. Orsola-Malpighi Hospital, Bologna, Italy (C.C.Q.); Scripps Research Institute, La Jolla, CA (J.N.B.); Cardiology and Geriatrics Sections, Department of Internal Medicine, Wake Forest School of Medicine, Winston-Salem, NC (D.W.K.); Department of Medicine-Geriatrics (T.H.M.) and Division of Cardiovascular Diseases (K.R.B.), University of Mississippi Medical Center, Jackson; and the Human Genetics Center, University of Texas Health Science Center School of Public Health, Houston (E.B.). Address reprint requests to Dr. Solomon at the Division of Cardiovascular Medicine, Brigham and Women's Hospital, 75 Francis St., Boston, MA 02115, or at ssolomon@rics.bwh.harvard.edu.

N EnglJ Med 2015;372:21-9. DOI: 10.1056/NEJMoal404852 Copyright (๑ 2015 Massachusetts Medical Society. 
MYLOID HEART DISEASE LEADS TO AN increase in ventricular wall thickness and stiffness of the heart. ${ }^{1}$ Abnormalities of transthyretin, a transport protein synthesized mainly by the liver, may lead to hereditary transthyretin-related amyloidosis. ${ }^{2}$ This disorder can be caused by any one of more than 100 point mutations in the transthyretin gene (TTR); the V122I variant, in which isoleucine is substituted for valine at position 122, is the most frequent mutation and occurs in 3 to $4 \%$ of black Americans. ${ }^{3-5}$ V122I reduces the stability of transthyretin tetramers, causing cardiac deposition of misfolded transthyretin monomers and resulting in an autosomal dominant cardiomyopathy that typically occurs during or after the sixth decade of life, with a penetrance believed to be as high as $80 \%$ among men. ${ }^{6-9}$ The variant has been associated with increased risks of heart failure and death.

Although progressive heart failure can develop in persons with echocardiographically typical amyloid cardiomyopathy, the relatively few published reports may have involved a highly selected group of persons with this variant and thus may not reflect its true clinical significance. ${ }^{9}$ We evaluated an unbiased sample of blacks who carry the V122I TTR variant to assess the effect of the variant on long-term morbidity and mortality and to determine the prevalence of abnormalities of cardiac structure and function in allele carriers beyond the sixth decade of life.

\section{METHODS}

\section{THE ATHEROSCLEROSIS RISK IN COMMUNITIES} STUDY

The Atherosclerosis Risk in Communities (ARIC) study is an ongoing, prospective, observational study that is designed to analyze the natural history of atherosclerotic diseases and risk factors for cardiovascular disease. The study rationale, design, and procedures have been published previously. ${ }^{10}$ Of the 15,792 persons 44 to 66 years of age who were recruited between 1987 and 1989 from four communities in the United States, 4266 (27\%) reported themselves to be black.

Follow-up visits occurred approximately every 3 years through 1998, with annual telephone interviews conducted between visits. A limited number of structural and functional echocardiographic variables were assessed in black participants during visit 3, which occurred between 1993 and 1995. Participants returned for visit 5 between June 2011 and August 2013, during which a broad range of clinical, laboratory, and echocardiographic data were obtained. The institutional review board at each site approved the study, and all participants provided written informed consent.

\section{STUDY POPULATION AND STUDY DESIGN}

Figure S1 in the Supplementary Appendix (available with the full text of this article at NEJM.org) shows the enrollment and follow-up of the study population included in the present analysis. The nonsynonymous V122I TTR variant (rs76992529) was determined by genotyping with the Illumina HumanExome BeadChip, version 1.0. The methods of genotyping, allele calling, and quality control have been published previously. ${ }^{11} \mathrm{~V} 122 \mathrm{I}$ TTR genotype information was unavailable for 410 of the 4266 black participants in the ARIC study, owing to a lack of available DNA, poor genotyping performance with the array, or a lack of consent, leaving 3856 participants in this analysis, of whom 124 (3\%) were carriers and 3732 were noncarriers (Fig. S1 in the Supplementary Appendix). Only $2(<0.1 \%)$ of the 10,893 nonblack participants who provided consent for genotyping had the V122I variant.

\section{EVENT ASCERTAIN MENT}

Outcomes were ascertained during follow-up visits for the ARIC study as well as through annual calls to participants, ongoing surveillance of health department certificate files, and review of local hospital-discharge lists (with outcomes determined on the basis of International Classification of Diseases codes) and death certificates. This method of ascertainment of outcomes has been reported previously and validated. ${ }^{12,13}$

\section{ECHOCARDIOGRAPHY}

Echocardiograms were obtained at visit 5 (between 2011 and 2013) according to a study-specific protocol and were analyzed in a core laboratory; the protocol and reproducibility have been described previously. ${ }^{14,15}$ Echocardiographic data were available for 1240 participants with genotype status. Left ventricular function was also assessed by means of speckle-tracking echocardiography (TomTec Imaging Systems). ${ }^{16,17}$ All echocardiographic assessments were performed by persons who were unaware of the participants' V122I genotype status. Echocardiograms showing a left ventricular wall thickness of more than $12 \mathrm{~mm}^{1,18}$ were reviewed by an investigator 
who was unaware of carrier status to identify features suggestive of cardiac amyloidosis, including granular sparkling of the ventricular myocardium, increased thickness of the atrioventricular valve or interatrial septum, and pericardial effusion.

\section{STATISTICAL ANALYSIS}

Clinical characteristics of ARIC study participants were assessed as described previously. ${ }^{19,20}$ Using Cox regression, we estimated age- and sexstratified hazard ratios to determine the association between the TTR variant and the risk of

\begin{tabular}{|c|c|c|c|c|c|c|}
\hline \multirow[t]{2}{*}{ Characteristic } & \multicolumn{3}{|c|}{$\begin{array}{c}\text { All Participants with Known V122I TTR } \\
\text { Genotype Status }\end{array}$} & \multicolumn{3}{|c|}{$\begin{array}{c}\text { Participants with Known V122I TTR } \\
\text { Genotype Status and Available } \\
\text { Echocardiographic Data }\end{array}$} \\
\hline & $\begin{array}{l}\text { Noncarriers } \\
(\mathrm{N}=3732)\end{array}$ & $\begin{array}{l}\text { Carriers } \\
(\mathrm{N}=124)\end{array}$ & P Value & $\begin{array}{l}\text { Noncarriers } \\
(\mathrm{N}=1194)\end{array}$ & $\begin{array}{l}\text { Carriers } \\
(\mathrm{N}=46)\end{array}$ & P Value \\
\hline \multicolumn{7}{|l|}{ Age $-y r$} \\
\hline Median & 53 & 52 & 0.39 & 50 & 50 & 0.32 \\
\hline IQR & $48-58$ & $48-57$ & & $47-54$ & $47-53$ & \\
\hline Male sex — no. (\%) & $1408(38)$ & $45(36)$ & 0.75 & $406(34)$ & $11(24)$ & 0.16 \\
\hline \multicolumn{7}{|l|}{ Body-mass index'́ } \\
\hline No. of patients with data & 3721 & 124 & & 1192 & 46 & \\
\hline Mean & $30 \pm 6$ & $29 \pm 6$ & 0.35 & $29 \pm 5$ & $28 \pm 5$ & 0.10 \\
\hline \multicolumn{7}{|l|}{ Systolic blood pressure } \\
\hline No. of patients with data & 3729 & 124 & & 1193 & 46 & \\
\hline Mean - mm Hg & $129 \pm 21$ & $131 \pm 20$ & 0.14 & $123 \pm 17$ & $126 \pm 16$ & 0.24 \\
\hline \multicolumn{7}{|l|}{ Diastolic blood pressure } \\
\hline No. of patients with data & 3729 & 124 & & 1193 & 46 & \\
\hline Mean - $\mathrm{mm} \mathrm{Hg}$ & $80 \pm 12$ & $82 \pm 13$ & 0.09 & $79 \pm 11$ & $81 \pm 12$ & 0.22 \\
\hline \multicolumn{7}{|l|}{ Heart rate } \\
\hline No. of patients with data & 3693 & 123 & & 1187 & 45 & \\
\hline Mean - beats/min & $67 \pm 11$ & $68 \pm 11$ & 0.24 & $66 \pm 10$ & $71 \pm 9$ & 0.001 \\
\hline $\begin{array}{l}\text { Systolic blood pressure } \geq 140 \mathrm{~mm} \mathrm{Hg} \\
\qquad \text { no./total no. (\%) }\end{array}$ & $937 / 3729(25)$ & $38 / 124(31)$ & 0.16 & $156 / 1193(13)$ & $10 / 46(22)$ & 0.09 \\
\hline $\begin{array}{l}\text { Diastolic blood pressure } \geq 90 \mathrm{~mm} \mathrm{Hg} \\
\quad \text { - no./total no. (\%) }\end{array}$ & $648 / 3729(17)$ & $30 / 124(24)$ & 0.05 & $163 / 1193(14)$ & $9 / 46(20)$ & 0.26 \\
\hline Hypertension — no./total no. (\%) & $2068 / 3714(56)$ & $72 / 123(59)$ & 0.53 & $515 / 1188(43)$ & $20 / 46(43)$ & 0.99 \\
\hline Antihypertensive medication — no./total no. (\%) & $1507 / 3712(41)$ & $50 / 123(41)$ & 0.99 & $384 / 1188(32)$ & $12 / 46(26)$ & 0.37 \\
\hline Diabetes — no./total no. (\%) & $715 / 3637(20)$ & $25 / 121(21)$ & 0.79 & $100 / 1167(9)$ & $3 / 46(7)$ & 0.79 \\
\hline Lipid-lowering medication — no./total no. (\%) & $53 / 3679(1)$ & $2 / 123(2)$ & 0.87 & 10/1174 (1) & $0 / 46$ & 1.00 \\
\hline Current smoker — no./total no. (\%) & $1103 / 3726(30)$ & $34 / 123(28)$ & 0.64 & $263 / 1192(22)$ & $8 / 46(17)$ & 0.45 \\
\hline \multicolumn{7}{|l|}{ Creatinine } \\
\hline No. of patients with data & 3628 & 123 & & 1165 & 46 & \\
\hline Median (IQR) - mg/dl & $0.9(0.8-1.0)$ & $0.9(0.8-1.0)$ & 0.65 & $0.9(0.8-1.0)$ & $0.9(0.8-1.0)$ & 0.66 \\
\hline \multicolumn{7}{|l|}{ Estimated GFR } \\
\hline No. of patients with data & 3628 & 123 & & 1065 & 46 & \\
\hline $\begin{array}{l}\text { Median }(\mathrm{IQR})-\mathrm{ml} / \mathrm{min} / 1.73 \mathrm{~m}^{2} \text { of body- } \\
\quad \text { surface area }\end{array}$ & $102(87-119)$ & $102(89-119)$ & 0.69 & $103(89-120)$ & $103(91-108)$ & 0.97 \\
\hline Prevalent heart failure - no./total no. (\%) & $245 / 3676(7)$ & $10 / 122(8)$ & 0.51 & $48 / 1185(4)$ & $4 / 46(9)$ & 0.12 \\
\hline
\end{tabular}

* Plus-minus values are means \pm SD. Between-group differences were analyzed with the use of Fisher's exact test or Pearson's chi-square test for categorical variables and the Mann-Whitney $U$ test or t-test for continuous variables. To convert values for creatinine values to micromoles per liter, multiply by 88.4. GFR denotes glomerular filtration rate, and IQR interquartile range.

$\dagger$ The body-mass index is the weight in kilograms divided by the square of the height in meters. 


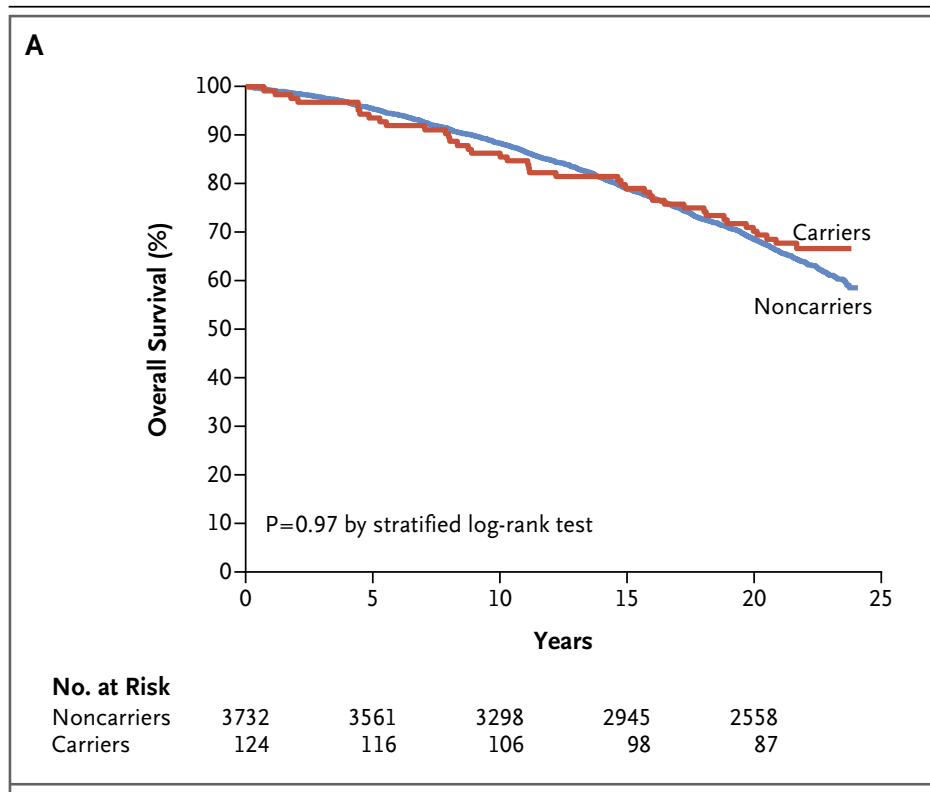

B

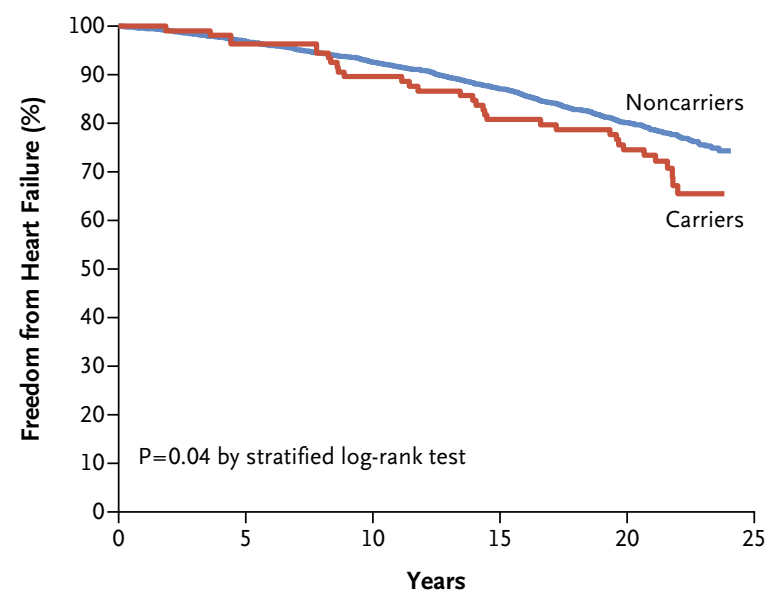

No. at Risk

Noncarriers Carriers

3431

$$
\begin{array}{r}
3431 \\
112
\end{array}
$$$$
3220
$$$$
2934
$$$$
92
$$$$
2566
$$$$
80
$$

2182

Figure 1. Kaplan-Meier Curves for Overall Survival and Freedom from Heart Failure, According to Genotype Status.

The analysis, which included black participants in the Atherosclerosis Risk in Communities study, compared carriers of the amyloidogenic V122I transthyretin variant with noncarriers of the variant. Survival estimates as a function of time from visit 1 were obtained.

death or incident heart failure. In the subgroup of participants who were alive and free from heart failure at 53 years of age, we estimated the mean time to death and time to incident heart failure, to a maximum of 30 years. In the heartfailure analyses, we excluded participants who had prevalent heart failure or for whom informa- tion on heart-failure status at baseline was missing. We used multiple imputation to account for missing echocardiographic data at visit 5 among living participants (see the Supplementary Appendix), and among participants who died before visit 5 , we compared the echocardiographic data of carriers and noncarriers from visit 3 . We assessed whether an age older than 80 years or an age of 80 years or younger modified the relationship between carrier status and mortality. Finally, we performed a meta-analysis of the effect of the variant allele on the incidence of heart failure by combining our results with those of the Cardiovascular Health Study (see the Supplementary Appendix). ${ }^{8}$ Two-sided P values of less than 0.05 were considered to indicate statistical significance. Analyses were performed with the use of Stata software, version 12.0 (StataCorp), or $\mathrm{R}$ software, version 3.0.1 (www.r-project.org). A detailed description of the statistical methods is available in the Supplementary Appendix.

\section{RESULTS}

\section{STUDY POPULATION}

At visit 1 , there were no significant differences between carriers and noncarriers with respect to demographic, clinical, and laboratory characteristics, including the prevalence of cardiovascular risk factors and heart failure (Table 1). Among participants who underwent echocardiography during visit 5 , the characteristics of carriers were similar to those of noncarriers, except that the heart rate was significantly higher among carriers (Table 1).

\section{OUTCOMES}

The median duration of follow-up was 21.5 years (interquartile range, 17.1 to 22.5), yielding 2334 person-years among carriers and 70,519 personyears among noncarriers. There were 41 deaths among carriers $(33 \%$; 1.76 deaths per 100 person-years) and 1382 deaths among noncarriers (37\%; 1.96 deaths per 100 person-years) (ageand sex-stratified hazard ratio among carriers, 0.99; $95 \%$ confidence interval [CI], 0.73 to 1.36 ; $\mathrm{P}=0.97$ ) (Fig. 1A). Incident heart failure was observed in 32 of 112 carriers $(29 \%$; 1.59 cases per 100 person-years) and 698 of 3431 noncarriers (20\%; 1.12 cases per 100 person-years) (stratified hazard ratio, 1.47; 95\% CI, 1.03 to $2.10 ; \mathrm{P}=0.04$ ) (Fig. 1B). Although we did not observe a signifi- 
cant interaction between carrier status and sex for either end point ( $\mathrm{P}=0.29$ for survival and $\mathrm{P}=0.87$ for freedom from heart failure), the hazard ratios for death and heart failure among carriers as compared with noncarriers were 1.20 (95\% CI, 0.77 to 1.86 ) and 1.54 (95\% CI, 0.88 to 2.71), respectively, among men and 0.84 (95\% CI, 0.54 to 1.32 ) and 1.42 (95\% CI, 0.89 to 2.26 ), respectively, among women (Fig. S2 in the Supplementary Appendix).

We did not observe a significant difference in the time to death after 53 years of age according to genotype status (Fig. 2A). In contrast, time free from heart failure during this interval was 2.0 years (95\% CI, 0.1 to 3.8) shorter among living carriers than among living noncarriers (23.9 years [ $95 \% \mathrm{CI}, 22.0$ to 25.7 ] vs. 25.9 years [ $95 \%$ CI, 25.6 to 26.2], $\mathrm{P}=0.04$ ) (Fig. 2B). We detected a nonsignificant trend toward an increase in the risk of death associated with mutation among participants older than 80 years of age (hazard ratio, 2.01; $95 \% \mathrm{CI}, 0.74$ to 5.47 ) versus those 80 years of age or younger (hazard ratio, 0.93; 95\% CI, 0.67 to 1.29 ; $\mathrm{P}=0.15$ for interaction). A metaanalysis in which the results of our study were combined with those of the Cardiovascular Health Study ${ }^{8}$ showed a combined hazard ratio for incident heart failure of 1.45 (95\% CI, 1.04 to 2.02; $\mathrm{P}=0.03$ ) among V122I TTR variant carriers (Fig. 3).

\section{CLINICAL AND ECHOCARDIOGRAPHIC PROFILES AT VISIT 5}

Among participants who attended visit 5, the clinical characteristics of carriers were similar to those of noncarriers, with the exception of the level of N-terminal pro-brain natriuretic peptide (NT-proBNP), which was significantly higher among carriers (Table S1 in the Supplementary Appendix). As compared with noncarriers, carriers had worse indexes of systolic function (e.g., a lower lateral mitral systolic velocity and a less negative value for global longitudinal strain) and diastolic function (e.g., a higher ratio of early mitral inflow velocity to lateral mitral early relaxation velocity and a higher ratio of early mitral inflow velocity to late mitral inflow velocity) in both adjusted and unadjusted analyses (Table 2). Only 5 carriers $(11 \%)$ and 111 noncarriers $(9 \%)$ had a mean left ventricular wall thickness of more than $1.2 \mathrm{~cm} .{ }^{18}$ Three carriers $(7 \%)$ and 11 noncarriers (1\%) showed severe symmetric left

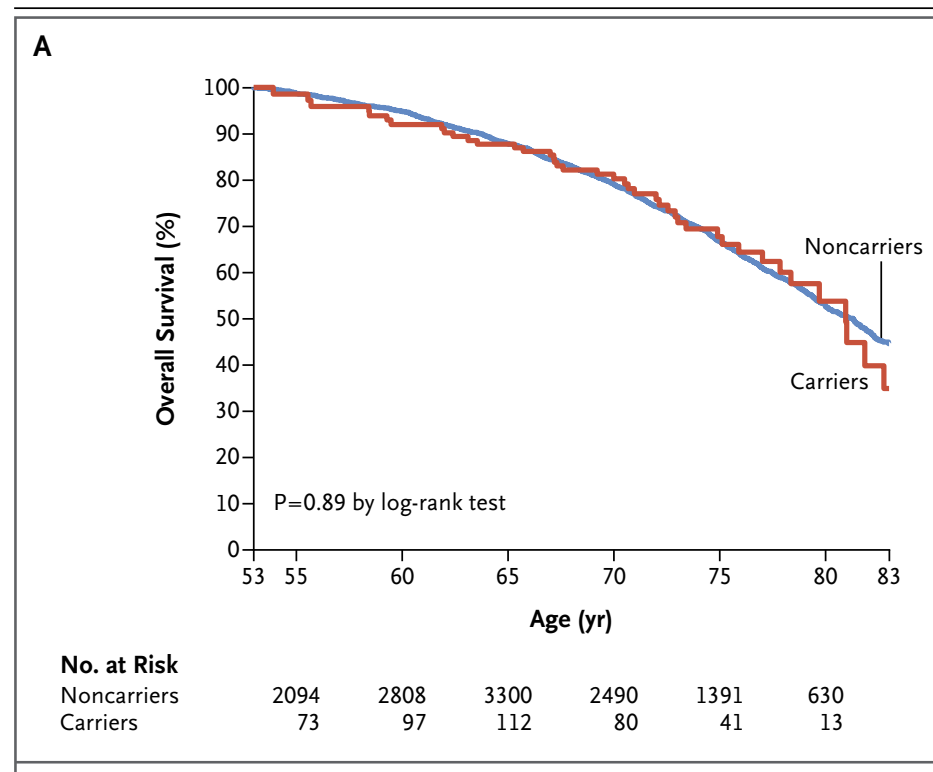

B

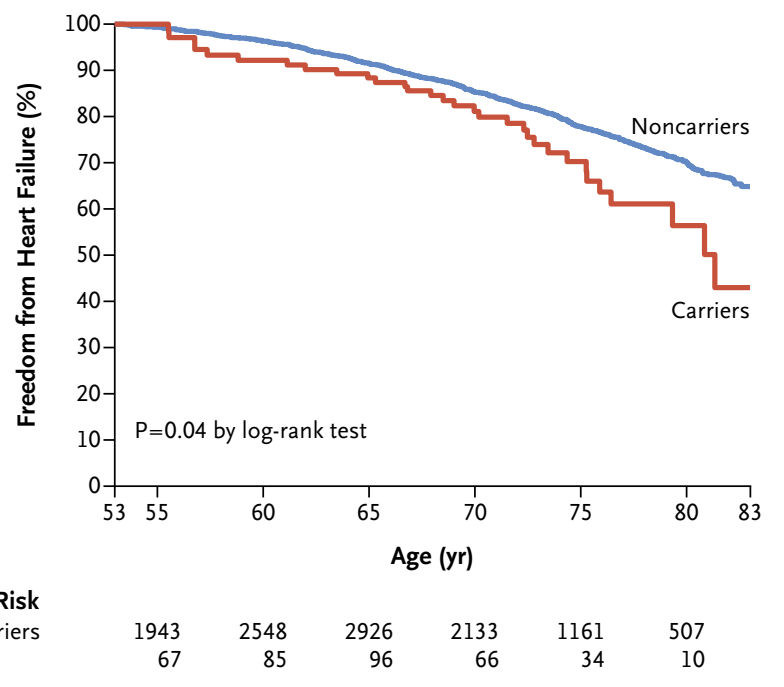

Figure 2. Kaplan-Meier Curves, with Age as the Underlying Time Variable, for Overall Survival and Freedom from Heart Failure, According to Genotype Status.

Participants with prevalent heart failure at the time of the first evaluation or for whom information on heart-failure status at baseline was missing were excluded from the analysis.

ventricular wall thickening and features suggestive of an infiltrative phenotype $(\mathrm{P}=0.01)$. Although genotype status was unknown for approximately $10 \%$ of black participants in the ARIC study, there were minimal differences between those with a known genotype status and those with an unknown status (Table S2 in the Supplementary Appendix). 


\begin{tabular}{|c|c|c|c|}
\hline \multicolumn{3}{|c|}{$\begin{array}{l}\text { Hazard Ratio among V122I TTR } \\
\text { Variant Carriers }(95 \% \mathrm{CI})\end{array}$} & $\begin{array}{l}\text { Weight } \\
(\%)\end{array}$ \\
\hline $\begin{array}{l}\text { Atherosclerosis Risk } \\
\text { in Communities }\end{array}$ & & $1.47(1.03-2.10)$ & 84.52 \\
\hline $\begin{array}{l}\text { Cardiovascular Health } \\
\text { Study }\end{array}$ & & $1.36(0.59-3.15)$ & 15.48 \\
\hline Overall $\left(\mathrm{I}^{2}=0.0 \%, \mathrm{P}=0.03\right)$ & & $1.45(1.04-2.02)$ & \multirow[t]{2}{*}{100.00} \\
\hline \multicolumn{2}{|r|}{1.00} & 15 & \\
\hline \multicolumn{4}{|c|}{$\begin{array}{l}\text { Figure 3. Hazard Ratios for Congestive Heart Failure among V122I TTR } \\
\text { Variant Carriers as Compared with Noncarriers in Two Population-Based } \\
\text { Longitudinal Studies. }\end{array}$} \\
\hline \multicolumn{4}{|c|}{$\begin{array}{l}\text { A fixed-effect meta-analysis was performed with the use of the inverse- } \\
\text { variance method. The size of each box is proportional to the number of } \\
\text { events in each study; horizontal lines indicate } 95 \% \text { confidence intervals. } \\
\text { The dashed red line indicates the overall hazard ratio, with the blue dia- } \\
\text { mond showing the } 95 \% \text { confidence interval for the overall hazard ratio. } \\
\text { The } I^{2} \text { statistic describes the percentage of variation across studies that } \\
\text { is due to heterogeneity rather than chance. }\end{array}$} \\
\hline
\end{tabular}

To account for missing echocardiographic data from living participants at visit 5 , we performed a multiple imputation analysis, which included 2154 noncarriers and 76 carriers. The results of these analyses were similar to those of the primary analyses, with significant differences observed between carriers and noncarriers in measures of systolic and diastolic function (Table S3 in the Supplementary Appendix). An analysis of limited echocardiographic data available for a subgroup of participants at visit 3 (1993 to 1995) showed that left ventricular wall thickness was increased to a similar extent in carriers and noncarriers who died before visit 5 (wall thickness, $1.25 \pm 0.21 \mathrm{~cm}$ and $1.27 \pm 0.24 \mathrm{~cm}$, respectively; $\mathrm{P}=0.70$ ).

\section{DISCUSSION}

We did not detect higher mortality among black carriers of the V122I TTR variant than among black noncarriers over long-term follow-up - a finding that was contrary to findings from a few small studies of patients who were referred primarily because of heart-failure symptoms or cardiac abnormalities; however, we did find a higher incidence of heart failure among carriers. The clinical penetrance of the V122I allele among men was shown in prior studies to be approximately $80 \% \%^{7-9}$; in contrast, the vast majority of carriers in our study, at an average age of 74 years and approximately two decades after initial evaluation, had no overt manifestations of amyloid cardiomyopathy. However, they did have subtle abnormalities of systolic and diastolic function, and their level of NT-proBNP was higher than that of noncarriers.

The published literature on the V122I TTR variant consistently describes a phenotype of restrictive cardiomyopathy with marked left ventricular wall thickening in the late stage of the disease after a latent period of asymptomatic increase in left ventricular mass, which suggests that a considerable amyloid load is required before the development of heart failure. Despite the high prevalence of the V122I variant among blacks, the clinical penetrance of this variant has not been clearly defined, although it is believed that the variant has no discernible effect on cardiac function and mortality before a person is 60 years of age. ${ }^{8}$

On the basis of prior reports, ${ }^{7-9}$ we anticipated that among elderly persons there would be significant differences in left ventricular wall thickness and other echocardiographic manifestations of cardiac amyloidosis between carriers and noncarriers. However, the prevalence of overt cardiac abnormalities among carriers was considerably lower than expected, suggesting that prior reports may have been influenced by referral bias. Nevertheless, the subtle structural and functional abnormalities and increased NTproBNP level in carriers could presage more severe abnormalities with increasing age. These findings suggest that there may be mechanisms other than extensive amyloid infiltration of the myocardium by which V122I contributes to heart failure, including a synergistic effect with other risk factors such as hypertension. Thus, carriers with little or no infiltration and minimal coexisting disease might remain asymptomatic, whereas those with other risk factors might manifest disease. This construct would be consistent with autopsy data from elderly V122I carriers, in whom some degree of amyloid deposition is almost universally present. ${ }^{3}$

Male sex has been described as predominant in the V122I TTR variant, with an estimated prevalence of 78 to $82 \% .{ }^{21,22}$ Despite a high proportion of women in the ARIC study, we did not observe any significant differences in either outcome according to sex, though the small number of men at visit 5 did not allow us to rule 


\begin{tabular}{|c|c|c|c|c|c|c|}
\hline \multirow[t]{2}{*}{ Variable } & \multicolumn{2}{|c|}{ Noncarriers ( $N=1194)$} & \multicolumn{2}{|c|}{ Carriers $(\mathrm{N}=46)$} & \multirow{2}{*}{$\begin{array}{l}\text { Unadjusted } \\
\text { P Value }\end{array}$} & \multirow[t]{2}{*}{$\begin{array}{l}\text { Adjusted } \\
\text { P Value' }\end{array}$} \\
\hline & Value & $\begin{array}{l}\text { No. of Patients } \\
\text { with Data }\end{array}$ & Value & $\begin{array}{l}\text { No. of Patients } \\
\text { with Data }\end{array}$ & & \\
\hline Interventricular septum thickness $-\mathrm{cm}$ & $1.1 \pm 0.2$ & 1187 & $1.1 \pm 0.2$ & 46 & 0.63 & 0.49 \\
\hline Posterior wall thickness $-\mathrm{cm}$ & $0.9 \pm 0.2$ & 1188 & $1.0 \pm 0.2$ & 46 & 0.08 & 0.04 \\
\hline Relative wall thicknesst & $0.44 \pm 0.09$ & 1184 & $0.47 \pm 0.16$ & 46 & 0.05 & 0.04 \\
\hline LV mass - g & $149 \pm 46$ & 1184 & $154 \pm 47$ & 46 & 0.48 & 0.31 \\
\hline \multicolumn{7}{|l|}{ LV wall thickness - no. of patients (\%) } \\
\hline$>1 \mathrm{~cm}$ & $521(44)$ & 1189 & $24(52)$ & 46 & 0.26 & 0.17 \\
\hline$>1.2 \mathrm{~cm}$ & $111(9)$ & 1189 & $5(11)$ & 46 & 0.73 & 0.61 \\
\hline Symmetric LV hypertrophy — no. of patients (\%) & $986(83)$ & 1185 & $40(87)$ & 46 & 0.50 & 0.50 \\
\hline \multicolumn{7}{|l|}{ LV mass index } \\
\hline Calculated as $\mathrm{g} / \mathrm{m}^{2}$ of body-surface area & $78 \pm 22$ & 1184 & $83 \pm 22$ & 46 & 0.16 & 0.11 \\
\hline Calculated as $\mathrm{g} / \mathrm{m}^{2.7}$ of height & $38 \pm 12$ & 1183 & $40 \pm 12$ & 46 & 0.38 & 0.45 \\
\hline LV end-diastolic diameter $-\mathrm{cm}$ & $4.3 \pm 0.5$ & 1184 & $4.3 \pm 0.6$ & 46 & 0.98 & 0.85 \\
\hline LV end-systolic diameter — cm & $2.6 \pm 0.5$ & 1184 & $2.7 \pm 0.7$ & 46 & 0.13 & 0.06 \\
\hline LV end-diastolic volume $-\mathrm{ml}$ & $84 \pm 25$ & 1125 & $88 \pm 27$ & 43 & 0.33 & 0.12 \\
\hline LV end-diastolic volume index $-\mathrm{ml} / \mathrm{m}^{2.7}$ of height & $21 \pm 6$ & 1124 & $22 \pm 6$ & 43 & 0.31 & 0.27 \\
\hline \multicolumn{7}{|l|}{ LV end-systolic volume - $\mathrm{ml}$} \\
\hline Median & 28 & 1125 & 28 & 43 & 0.43 & 0.14 \\
\hline IQR & $22-35$ & & $22-37$ & & & \\
\hline \multicolumn{7}{|l|}{ LV end-systolic volume index $-\mathrm{ml} / \mathrm{m}^{2.7}$ of height } \\
\hline Median & 7.1 & 1125 & 7.1 & 43 & 0.27 & 0.21 \\
\hline IQR & $5.8-8.8$ & & $6.0-9.4$ & & & \\
\hline LV ejection fraction — \% & $65 \pm 7$ & 1125 & $63 \pm 9$ & 43 & 0.27 & 0.16 \\
\hline Stroke volume $-\mathrm{ml}$ & $65 \pm 15$ & 1185 & $62 \pm 15$ & 45 & 0.20 & 0.18 \\
\hline \multicolumn{7}{|l|}{ Stroke volume index } \\
\hline Calculated as $\mathrm{ml} / \mathrm{m}^{2}$ of body-surface area & $34 \pm 8$ & 1184 & $34 \pm 9$ & 45 & 0.57 & 0.46 \\
\hline Calculated as $\mathrm{ml} / \mathrm{m}^{2.7}$ of height & $17 \pm 4$ & 1185 & $16 \pm 5$ & 45 & 0.32 & 0.12 \\
\hline Cardiac output — liters/min & $4.1 \pm 1.1$ & 1175 & $4.1 \pm 1.0$ & 45 & 0.79 & 0.73 \\
\hline Cardiac index - liters $/ \mathrm{min} / \mathrm{m}^{2}$ of body-surface area & $2.2 \pm 0.5$ & 1173 & $2.2 \pm 0.5$ & 45 & 0.64 & 0.76 \\
\hline \multicolumn{7}{|l|}{ Left atrial volume index } \\
\hline Calculated as $\mathrm{ml} / \mathrm{m}^{2}$ of body-surface area & $26 \pm 9$ & 1178 & $28 \pm 10$ & 45 & 0.12 & 0.11 \\
\hline Calculated as $\mathrm{ml} / \mathrm{m}^{2.7}$ of height & $13 \pm 5$ & 1177 & $14 \pm 5$ & 45 & 0.31 & 0.38 \\
\hline E-wave deceleration time $-\mathrm{msec}$ & $197 \pm 44$ & 1189 & $187 \pm 45$ & 45 & 0.12 & 0.14 \\
\hline Ratio of early mitral inflow velocity to late mitral inflow velocity & $0.8 \pm 0.3$ & 1161 & $0.9 \pm 0.5$ & 43 & 0.02 & 0.02 \\
\hline Lateral mitral early relaxation velocity $-\mathrm{cm} / \mathrm{sec}$ & $7.1 \pm 2.1$ & 1188 & $6.5 \pm 1.9$ & 45 & 0.11 & 0.10 \\
\hline $\begin{array}{l}\text { Ratio of early mitral inflow velocity to lateral mitral early } \\
\text { relaxation velocity }\end{array}$ & $10.1 \pm 3.9$ & 1186 & $11.6 \pm 4.3$ & 45 & 0.01 & 0.01 \\
\hline Lateral mitral systolic velocity $-\mathrm{cm} / \mathrm{sec}$ & $7.2 \pm 1.6$ & 1159 & $6.7 \pm 1.5$ & 44 & 0.05 & 0.04 \\
\hline Tricuspid regurgitation velocity $-\mathrm{cm} / \mathrm{sec}$ & $240 \pm 32$ & 712 & $242 \pm 30$ & 29 & 0.74 & 0.73 \\
\hline LV global longitudinal strain — \% & $-17.4 \pm 2.8$ & 1125 & $-16.6 \pm 2.6$ & 41 & 0.05 & 0.02 \\
\hline Abnormal LV global longitudinal strain — no. of patients (\%) & $902(80)$ & 1125 & $36(88)$ & 41 & 0.23 & 0.18 \\
\hline Basal LV longitudinal strain — \% & $-16.1 \pm 3.9$ & 1125 & $-15.2 \pm 3.5$ & 41 & 0.14 & 0.10 \\
\hline Mid-LV longitudinal strain — \% & $-16.7 \pm 3.2$ & 1125 & $-159 \pm 3.7$ & 41 & 0.13 & 0.07 \\
\hline Apical LV longitudinal strain — \% & $-19.5 \pm 5.0$ & 1125 & $-18.6 \pm 4.0$ & 41 & 0.23 & 0.17 \\
\hline LV global radial strain — \% & $24.3 \pm 8.2$ & 1125 & $22.8 \pm 7.6$ & 41 & 0.25 & 0.22 \\
\hline LV global circumferential strain — \% & $-26.9 \pm 4.4$ & 836 & $-26.5 \pm 6.2$ & 34 & 0.58 & 0.40 \\
\hline
\end{tabular}

* Plus-minus values are means \pm SD. Between-group differences were analyzed with the use of Fisher's exact test or Pearson's chi-square test for categorical variables and the Mann-Whitney $U$ test or t-test for continuous variables. LV denotes left ventricular.

$\dagger$ The values were adjusted according to age and sex with the use of linear regression or logistic-regression models.

$\neq$ Relative wall thickness was calculated as $(2 \times$ the posterior wall thickness measured at end diastole in centimeters) $\div$ the end-diastolic diameter of the left ventricle in centimeters. 
out differences in cardiac structure and function according to sex.

Some limitations of this analysis should be noted. First, the absolute number of V122I carriers was low. Second, genotype status was unknown for approximately $10 \%$ of blacks enrolled in the ARIC study, although there were minimal differences between those with a known genotype status and those with an unknown status, making substantial bias unlikely. Third, we cannot exclude the possibility that the low number of male carriers as compared with female carriers at visit 5 was due to more aggressive cardiac amyloid involvement in men. However, the absence of echocardiographic abnormalities in those who died before visit 5 argues against this, and the sex distribution according to carrier status at visit 5 was proportional to that in the recruited cohort. Because endomyocardial biopsy specimens or autopsy specimens were not available, we cannot rule out some degree of cardiac involvement in carriers. Finally, we cannot rule out an increase in mortality among carriers of up to $36 \%$, and our data raise the possibility that excess mortality may be associated with increasing age. Thus, increased mortality might be observed in a larger or older cohort.

In summary, we did not detect a greater risk of death among V122I TTR allele carriers than among noncarriers, although we did observe an increased risk of heart failure. The prevalence of overt cardiac abnormalities among carriers was lower than expected, although carriers had subtle impairments of systolic and diastolic function. These data suggest that amyloidosis associated with the V122I TTR variant may be more benign than previously thought, although elderly persons who carry this variant may be at modestly increased risk for heart failure.

Supported by contracts from the National Heart, Lung, and Blood Institute (NHLBI) (HHSN268201100005C, HHSN268201100006C, HHSN268201100007C, HHSN268201100008C, HHSN268201100009C, HHSN268201100010C, HHSN268201100011C and HHSN268201100012C), a cooperative agreement from the NHLBI (NHLBI-HC-11-08, to Brigham and Women's Hospital), and a grant from the National Institutes of Health (R01 AG19259, to Dr. Buxbaum).

Disclosure forms provided by the authors are available with the full text of this article at NEJM.org.

We thank the staff and participants of the Atherosclerosis Risk in Communities study for their important contributions.
REFERENCES

1. Falk RH, Dubrey SW. Amyloid heart disease. Prog Cardiovasc Dis 2010;52:34761. [Erratum, Prog Cardiovasc Dis 2010; 52:445-7.]

2. Ando Y, Nakamura M, Araki S. Transthyretin-related familial amyloidotic polyneuropathy. Arch Neurol 2005;62:1057-62.

3. Jacobson DR, Pastore RD, Yaghoubian $\mathrm{R}$, et al. Variant-sequence transthyretin (isoleucine 122) in late-onset cardiac amyloidosis in black Americans. N Engl J Med 1997;336:466-73.

4. Rapezzi C, Quarta CC, Obici L, et al. Disease profile and differential diagnosis of hereditary transthyretin-related amyloidosis with exclusively cardiac phenotype: an Italian perspective. Eur Heart J 2013;34:520-8.

5. Rowczenio D, Wechalekar A. Mutations in hereditary amyloidosis (http:// www.amyloidosismutations.com/mut -attr.php).

6. Jiang X, Buxbaum JN, Kelly JW. The V122I cardiomyopathy variant of transthyretin increases the velocity of ratelimiting tetramer dissociation, resulting in accelerated amyloidosis. Proc Natl Acad Sci U S A 2001;98:14943-8.

7. Jacobson DR, Gorevic PD, Buxbaum JN. A homozygous transthyretin variant associated with senile systemic amyloidosis: evidence for a late-onset disease of genetic etiology. Am J Hum Genet 1990; 47:127-36.
8. Buxbaum J, Alexander A, Koziol J, Tagoe C, Fox E, Kitzman D. Significance of the amyloidogenic transthyretin Val 122 Ile allele in African Americans in the Arteriosclerosis Risk in Communities (ARIC) and Cardiovascular Health (CHS) Studies. Am Heart J 2010;159:864-70.

9. Jacobson D, Tagoe C, Schwartzbard A, Shah A, Koziol J, Buxbaum J. Relation of clinical, echocardiographic and electrocardiographic features of cardiac amyloidosis to the presence of the transthyretin V122I allele in older African-American men. Am J Cardiol 2011;108:440-4. 10. The ARIC Investigators. The Atherosclerosis Risk in Communities (ARIC) Study: design and objectives. Am J Epidemiol 1989;129:687-702.

11. Grove ML, Yu B, Cochran BJ, et al Best practices and joint calling of the $\mathrm{Hu}-$ manExome BeadChip: the CHARGE Consortium. PLoS One 2013;8(7):e68095.

12. Loehr LR, Rosamond WD, Chang PP, Folsom AR, Chambless LE. Heart failure incidence and survival (from the Atherosclerosis Risk in Communities study). Am J Cardiol 2008;101:1016-22.

13. Rosamond WD, Chang PP, Baggett C et al. Classification of heart failure in the Atherosclerosis Risk in Communities (ARIC) study: a comparison of diagnostic criteria. Circ Heart Fail 2012;5:152-9.

14. Shah AM, Cheng S, Skali H, et al. Rationale and design of a multicenter echo- cardiographic study to assess the relationship between cardiac structure and function and heart failure risk in a biracial cohort of community-dwelling elderly persons: the Atherosclerosis Risk in Communities study. Circ Cardiovasc Imaging 2014;7:173-81.

15. Lang RM, Bierig M, Devereux RB, et al. Recommendations for chamber quantification: a report from the American Society of Echocardiography's Guidelines and Standards Committee and the Chamber Quantification Writing Group, developed in conjunction with the European Association of Echocardiography, a branch of the European Society of Cardiology. J Am Soc Echocardiogr 2005;18:1440-63.

16. Cheng S, Larson MG, McCabe EL, et al. Reproducibility of speckle-trackingbased strain measures of left ventricular function in a community-based study. J Am Soc Echocardiogr 2013;26:1258-66. 17. Yingchoncharoen $\mathrm{T}$, Agarwal $\mathrm{S}$, Popović ZB, Marwick TH. Normal ranges of left ventricular strain: a meta-analysis. J Am Soc Echocardiogr 2013;26:185-91. 18. Gertz MA, Comenzo R, Falk RH, et al. Definition of organ involvement and treatment response in immunoglobulin light chain amyloidosis (AL): a consensus opinion from the 10th International Symposium on Amyloid and Amyloidosis, Tours, France, 18-22 April 2004. Am J Hematol 2005;79:319-28. 
19. Folsom AR, Yamagishi K, Hozawa A, Chambless LE. Absolute and attributable risks of heart failure incidence in relation to optimal risk factors. Circ Heart Fail 2009;2:11-7.

20. Kottgen A, Russell SD, Loehr LR, et al. Reduced kidney function as a risk factor for incident heart failure: the Atherosclerosis Risk in Communities (ARIC) study. J Am Soc Nephrol 2007;18:130715.

21. Coelho T, Maurer MS, Suhr OB. THAOS - The Transthyretin Amyloidosis Outcomes Survey: initial report on clinical manifestations in patients with hereditary and wild-type transthyretin amyloidosis. Curr Med Res Opin 2013;29: 63-76.
22. Bhuiyan T, Helmke S, Patel AR, et al. Pressure-volume relationships in patients with transthyretin (ATTR) cardiac amyloidosis secondary to V122I mutations and wild-type transthyretin: Transthyretin Cardiac Amyloid Study (TRACS). Circ Heart Fail 2011;4:121-8.

Copyright (๑) 2015 Massachusetts Medical Society.

The New England Journal of Medicine 